\title{
Waiting and the Duration of Time: The Critique of Everyday Life in Jia Zhangke's Platform
}

\section{Wenjin Cui}

\section{(2) OpenEdition}

\section{Journals}

Electronic version

URL: https://journals.openedition.org/chinaperspectives/10123

DOI: 10.4000/chinaperspectives.10123

ISSN: 1996-4617

\section{Publisher}

Centre d'étude français sur la Chine contemporaine

Printed version

Date of publication: 1 June 2020

ISSN: 2070-3449

\section{Electronic reference}

Wenjin Cui, "Waiting and the Duration of Time: The Critique of Everyday Life in Jia Zhangke's Platform",

China Perspectives [Online], 2020-2 | 2020, Online since 01 June 2020, connection on 06 July 2021.

URL: http://journals.openedition.org/chinaperspectives/10123 ; DOI: https://doi.org/10.4000/

chinaperspectives.10123 


\title{
Waiting and the Duration of Time: The Critique of Everyday Life in jia Zhangke's Platform
}

\author{
WENJIN CUI
}

\begin{abstract}
This paper examines the duration of time in everyday life as depicted in Jia Zhangke's 賈樟柯 second feature film, Platform 站台 (Zhantai) (2000). In light of the Bergsonian notion of time and Deleuze's creative application of this notion in the realm of cinema, it demonstrates how the duration of time - the core of the experience of waiting depicted in the film - is brought out in the film's narrative structure, cinematic devices, and acting style. Fundamental to the film's creative endeavour is the attempt to capture the resistance of the present moment against the weight of its own virtual double, which is to say, to unearth the gaps and lacunae that lie beneath the temporal continuum assumed in our habitual way of living. On the basis of this particular vision of time, the film offers a critique of everyday life as the very site where the platitude of existing norms of culture is laid bare and where the unbearable pressure of time forces us to question the value of all existing possibilities.
\end{abstract}

KEYWORDS:Waiting, duration of time, virtuality, everyday life, Jia Zhangke, Platform.

$\int \mathrm{i}$ t ia Zhangke's 賈樟柯 film oeuvre has been commonly discussed within the framework of realism (Cui 2006; McGrath 2007; Veg 2007; Berry 2009; Zhang 2009; Cheung 2010). In terms of content, his films are praised for bringing into view a social stratum often neglected in mainstream representations of contemporary China, namely, the mundane and rough everyday reality experienced on the margins of the post-socialist reforms that China has undergone in the past few decades. At the level of form, comments are often made regarding their employment of location shooting, non-professional actors, authentic sound (dialects, etc.), the episodic narrative, and the long take - all of which are classical aesthetic staples that Bazin established in his well-known conception of cinematic realism. Finally, in terms of their external context, they are usually linked to the New Documentary movement (Xin jilupian yundong 新紀錄片運動) within mainland China and a broadly defined realist tradition in world cinema, including sources of inspiration explicitly indicated by jia himself (Italian neorealism, Yasujirō Ozu, and Hou Hsiao-hsien 侯孝賢), as well as various directors active in the contemporary independent film scene.

While these discussions have shed light on a wide range of issues crucial to our understanding of jia Zhangke's films, many suffer from a weakness that is frequently seen in discussions of realism - the conflation of realism as a mode of representation with reality as the object of artistic portrayal. Many studies focus on the unique social content made visible in Jia's films, especially vis-à-vis the works of Fifth Generation directors and contemporary mainstream and commercial productions. When attention is directed to the issue of form, emphasis is mostly placed on how the aesthetic means employed in the films contribute to their faithful rendering of reality, implying that the use of authentic materials (setting, actors, and sound) can be automatically transferred into the realism of an artistic work, and that the episodic narrative and the long take are primarily about recording reality in an already existing spatial-temporal continuity. Perhaps in reaction to these rather simplified approaches, some scholarship has turned to stress certain presumably non-realist aspects of Jia's films, whether it is the fictional elements in their content, their use of allegorical and symbolic means of expression, or their intertextual references to various literary and artistic traditions (Li 2009; Byrnes 2012; Zheng 2013). Although not all of these studies take an explicit stand against the realist approach, they are reminders that any serious claim of Jia's realism cannot afford to neglect its aesthetic complexity.

This article does not aim to defend or question the claim of jia Zhangke's realism per se. I do think that it is generally valid to place his works in the tradition of Bazinian realism, as long as we do not reduce the latter to a dogmatic set of aesthetic attributes that purports to enable a transparent copy of reality. In this article, instead of making an overarching reflection on the specific kind of realism that jia has created in his works, I intend to focus on how he treats the experience of time in everyday life. This subject is not only fundamental to jia Zhangke's creative endeavours, but also stands at the centre of general discussions of cinematic realism (Nagib 2011; De Luca 2013). While current scholarship has rightly taken note of the preservation of temporal unity that jia achieved through the aesthetic devices of the episodic narrative and the long take, they tend to explain this particular feature in terms of its faithfulness to reality. The basic goal of my article is to show that the key matter lies rather in its capturing of the virtuality of time, in the sense that Bergson gives it in his well-known conception of time as duration. Through a recourse to the Bergsonian notion of time and Deleuze's conception of "time-image" (Deleuze 1989), I hope to move beyond the undertheorized understanding of duration that has prevailed in current 
discussions of Jia Zhangke's films. I propose that Jia Zhangke's presentation of the experience of duration aims to capture the resistance of the present moment against the weight of its own virtual double, which is to say, to unearth the gaps and lacunae that lie beneath the temporal continuum of our habitual way of living.

The following discussions will proceed mainly through a close reading of Platform (2000), ${ }^{1}$ jia's second feature film. Not only is it his most personal and aesthetically most accomplished work, but more importantly, this film provides a pure and concentrated expression of the everyday attitude of waiting - understood in the existential sense as an inactive state (Heidegger 2010) - that is central to jia Zhangke's cinematic presentation of time as a whole. To the extent that Jia's films generally depict uneventful, loosely connected everyday episodes rather than dramatic, tightly knit actions, we can say that the experience of waiting constitutes an implicit dimension of all of them. However, in his other films, this dimension is usually subordinated to other themes, such as the alienation of human relationships in Xiao Wu (1997) and the local effects of globalisation in The World (2004). It is only in Platform that this distinct existential mood acquires a dominant presence. As is well-captured in its title, the sense of a waiting that knows no fulfilment and that is never-ending figures as an overarching mood of the film. ${ }^{2}$ It should be stressed that waiting is not a diegetic theme that forms part of the film's narrative, which revolves around the relationship of two young couples - members of a performance troupe (wengongtuan 文工團) in a small county in northern China - as they experience the tremendous historical change that took place during the first decade of the reform era (1979-1989). However, it might be said to be a common everyday attitude that defines the protagonists beyond whatever they are occupied with. The characters go about their everyday business in life, whether courting their loved ones, hanging out with friends, following the latest trends, or going on a tour with their performing troupe. Yet beneath all these conscious activities, they are really just waiting - waiting for something to happen, although nothing ever does.

The socio-historical content registered in the film's depiction of waiting is apparent. As Jia $(2003 ; 2009)$ himself noted in various interviews and essays, the vague anticipation of the future and the constant falling short of such anticipation is particularly characteristic of the first decade of the reform era, as Chinese society first embarked upon a process of development and selfliberation. Contrary to the official narrative of the linear progress of history, what jia attempts to capture in Platform, as in his other films, is primarily the sense of loss and alienation that ordinary people experience in the face of dramatic historical change. In this regard, the everyday attitude of waiting conveys Jia's particular understanding of the experience of ordinary life in contemporary China.

While acknowledging the socio-historical specificity of what waiting signifies in Platform, however, my discussion focusses on its existential and aesthetic dimensions. Specifically, I will demonstrate how the duration of time constitutes the core of the experience of waiting captured in the film, and how it is brought out in the film's narrative structure, cinematic devices, and acting style. Furthermore, I will also explore how this particular vision of time contributes to contemporary discussions of everyday life in its focus on the banality of everyday experience. Drawing upon Deleuze's insightful observations on everyday life in his discussion of the invention of the timeimage in post-war cinema, and in reference to various representations of everyday life in contemporary Chinese literature and film, I will discuss how the film offers a critique of everyday life as the very site where the platitude of existing norms of culture is laid bare and where the unbearable pressure of time forces us to question the value of all existing possibilities. In particular, focusing on what may be called moments of eruption captured in Platform and more notably in $A$ Touch of $\sin (2013)$, I will consider how this critique gestures towards the creative potential harboured in the unbearable banality of everyday life.

\section{Waiting and the duration of time}

Regarding the experience of waiting, Bergson has remarked: "If I want to mix a glass of sugar and water, I must, willy-nilly, wait until the sugar melts" (1998: 9). Between the moment when the sugar is put in the water and when the sugar melts, there is a duration that we cannot eliminate and of which we are made aware in the experience of waiting. Contrary to the scientific view and our conventional understanding, which sees waiting as the purely empty, negative side of the future moment of action, Bergson argues that the time it takes for the sugar to melt involves a qualitative change in the subject who is waiting for time to pass. On such an occasion, time is not merely thought, but actually lived. To wait is to experience the passing of time, not as the quantitative succession from one moment to the next, but as the indivisible, continuous process of change.

This particular experience of waiting is precisely what is depicted in Jia's Platform. The film is not structured around the two limiting moments of waiting: the before and the after. Rather, it gives us the intervals of waiting, or the lived experience of time. Instead of a dramatic, tightly knit storyline, the film is composed of slow-paced scenes of everyday life in which not much happens and between which the narrative connection is quite loose. The ten years of life covered in the film are punctuated by a few recognisable political and cultural markers, such as the $35^{\text {th }}$ anniversary of the founding of PRC, the privatisation of the performance troupe, the change of fashions in popular culture, as well as various stages of the relationship between the young couples, such as when they advance their love, when they break up, when they get back together, etc. These nodal points are not devoid of dramatic interest, and would normally have been treated as the central axis of the narrative. However, in this film they are presented in an intentionally undramatic manner and are blended into thematically unrelated scenes. One gets the feeling that the scenes often start from a random moment and end with no visible break in a continuing state of existence. Rather than being woven together by a strong logic of action that leaves no gap, the situations endure in themselves while at the same time being exposed to lacunae that set them apart.

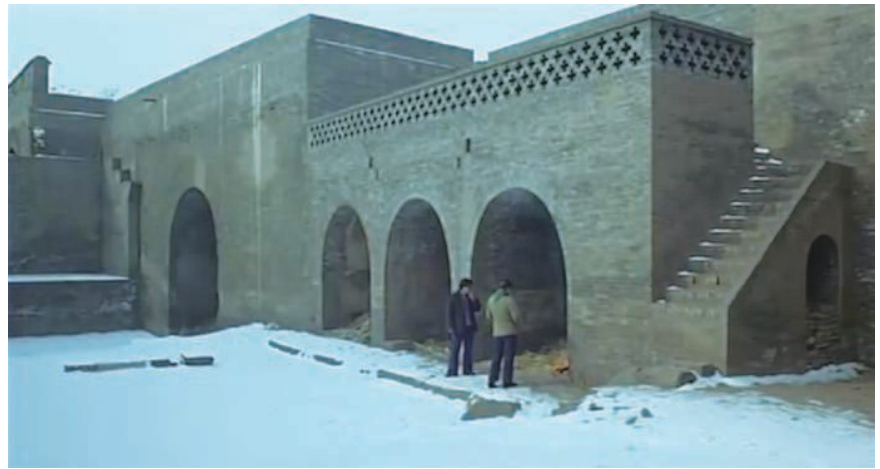

Figure 1. Hanging out under the city wall in Platform. Credit: Screenshot by the author.

1. Please see the filmography below for full details.

2. The film's title is taken from a 1980s pop song, the lyrics of which convey this particular sense of waiting. The song itself appears twice in the film, including in a scene that is evidently meant to be a kind of lyrical kernel of the entire film. 
In place of dramatic tension, however, we are presented with a tension on another front, namely, the struggle against time. The sparse conversations between the two main protagonists, Cui Mingliang 崔明亮 and Yin Ruijuan 尹瑞娟, the content of which hardly touches on their feelings for one another, along with their subtle bodily gestures mostly devoid of narrative context, are charged with a sense of the passing of time precisely because the time is not filled with action. In one of the early scenes, when the two are hanging out under the city wall, after a light conversation that hints at their relationship, they both fall into silence, while a fire behind them quietly leaps forward and a short musical phrase rises up to fill the scene. Their silence, which is lifted into a somewhat surreal state by the fire and the music, might be viewed as time itself appearing in person. No longer the substratum that supports what passes through it, time here is presented as the abyss into which things disappear and against which things arise. In another scene, we see Yin Ruijuan dancing to the radio in her office, and then, with the same song playing in the background, we see her riding through the city on a scooter and Cui Mingliang sitting on the back of a truck possibly leaving the city. These three little segments appear towards the end of the film, when life has clearly become a disappointment for them and shortly before they settle down as a couple. As they dance or ride through the cinematic space, what is compressed in their movement is none other than all their fallen hopes of bygone years and their restrained resignation to an unknown future.

Significantly, the intention to capture the pressure of time is cited by jia as a major reason for the film's signature use of long takes. ${ }^{3}$ In an interview Jia says:

What I like most in a long take is that it preserves real time, it keeps time intact. (...) In Platform, the characters have a relationship with time. You see two people smoking and talking aimlessly for a long time. Nothing happens plot wise but at the same time, time itself is kept intact. In that long and tedious passage of time, nothing significant happens, they are waiting. Only through time can you convey this. If I were to break up that scene which lasts for six or seven minutes into several cuts, then you lose that sense of deadlock. The deadlock that exists between humans and time, the camera and its subject. Everybody experiences the monotony of time passing where nothing that is noteworthy occurs. ${ }^{4}$

Jia's expressions, such as "preserves real time" and "keeps time intact," could suggest a kind of naive realism. However, it is clear that "real," "intact" time would be meaningless for him if it was not captured in a "deadlock" relationship with the human subjects. The key to the issue is not to passively copy any purely objective, independent reality, but to bring out a specific relationship between reality and the human subjects who experience it. The specific relationship captured in Jia's films is predominantly one of passivity, as opposed to conventional plot-oriented films, where we find agents of action imposing their activities on the course of things. Nevertheless, passivity is found inside the films and is brought out by the camera through conscious construction, rather than being located outside the films and presupposing the camera's slavish recording of a pre-existing reality. The "real," "intact" time jia seeks to "preserve," one might say, is not already out there in and of itself, but can only exist in the "monotony" one feels when faced with it - as the "tedious passage" through which one must wait.

Instead of taking the indivisibility of time that jia emphasises in the naive sense of an uninterrupted flow of a certain amount of time, we need to seek its meaning from another direction. Bergson's explication of the experience of waiting presupposes the understanding of time as duration, that is, as the indivisible, continuous process of qualitative change. While the conventional conception of time is locked into the constantly passing present, reducing the past to a former present and the future to a present yet to come, Bergson (1998: 4) envisions the duration of time as "the continuous progress of the past which gnaws into the future and which swells as it advances." The past is not born only when the present no longer is, but is always already there as the virtual double of the present and as the force that incessantly presses the present into an open future. Time is indivisible, in the sense that it is "the preservation of the past in the present" (Bergson 2007: 129), or as Deleuze (1988: 42) puts it, "it is the virtual insofar as it is actualized, in the course of being actualized."

The virtuality of time is the key to understanding the "deadlock" relationship between man and time that is fundamental to Platform. The pressure of time that jia attempts to capture with the use of long takes lies in the totality of the past that presses into the present, or in the virtual double that weighs upon present existence. To the extent that the virtuality of time does not depend on the blocking out of an undivided chunk of time, the long take is not a necessary means to bring out this dimension, as Jia's words might lead us to think. ${ }^{5}$ It is true that the long take is a key cinematic device jia has chosen, but that should not make us conflate the quantitative block of time that the long take automatically amasses with the qualitative unity of time it must consciously bring about. If the use of long takes does create a favourable condition for capturing the virtual dimension of time, its potential would fall short in the film without the coordination of two other key cinematic elements: empty space and dissonant sound.

\section{Figures of virtuality: Empty space and dissonant sound}

A striking feature of the film, one that most effectively heightens our sense of the virtuality of time, is the presence of empty spaces. ${ }^{6}$ For instance, in the memorable scene when Cui Mingliang and Yin Ruijuan have a conversation about their relationship on the city wall, the camera stands still at a certain moment, while the two characters move back and forth between a spot we can see and a spot that is hidden behind a wall, with moments when both characters are offscreen and we are faced with just the empty space of the city wall. There is something going on in this shot, but the point is that the camera is not following the movement of the characters, but gives us an empty landscape instead. To give another example, in a later scene when Cui Mingliang wanders on a street with some friends, the camera follows them for a few seconds, but then stops and fixates on a large billboard that blocks about two-thirds of the screen while the characters walk further and disappear from our view behind a street corner. We then see two people running out of a store and turning around the same corner. After a long interval, we hear shouts and see two people running back into our view and then out in the distance, with Cui Mingliang chasing after them

3. The use of long take is a hallmark of Jia's films in general, and it is given perhaps the most extended use in this particular one. Many shots are more than two minutes long, and most shots are at least half a minute.

4. Jia 2001. See also Jia 2003: 32

5. Deleuze provides ample instances when a certain kind of cutting is used to capture the virtuality of time. For instance, Ozu's use of the montage-cut (1989: 13), or Godard's creation of "unlinked" image (1989: 183).

6. Cf. Noël Burch's famous discussion of Ozu's use of "pillow shots" or "cutaway still-lifes" (1979: 160-1) 
and then being dragged by his friend back towards us, his head bleeding. It is clear that a fight occurred around the corner, but instead of showing us the fight scene, the camera blocks our view with a large billboard. ${ }^{\text {? }}$

How do such empty spaces contribute to our perception of the virtual dimension of time? The crucial point lies in the disruption they bring to our conventional perception of time as the mechanical succession of the divisible instants of before and after. While a regular movement takes us from one present moment to another in the process of carving out a continuous space, the attention shifted from action to the empty space creates the sense that the present sinks into an abyss where it is not, and that this abyss of time coexists with the present as its virtual double. The voiding of space, in other words, reveals the limit of the actual present, or the virtual presence of the past. What we are given is not only the present moment as it is actually there, but also the past that it is already becoming.

This explains the contemplative or even dreamy air that the presence of the empty space always creates in the film. As the two lovers alternately or simultaneously move out of view during their conversation on the city wall, the scene acquires a subtle sense of unreality, as if they are not just moving out of the physical space, but rather disappearing into the other side of a mirror. Similarly, as the camera directs our view to the billboard while the characters walk around the corner, have their fight and run back, we have the feeling that they have not just gone around the corner, but to another land altogether. The relationship between what is seen on the screen and what is hidden offscreen does not seem to be primarily one of spatial extension, even though they are technically adjacent parts of the same physical set. Instead of being a place from which human activities are merely temporarily removed and to which they may return at any moment, the empty space shown on the screen seems to assume a more absolute status as a force that corrodes whatever is happening in the background. The conversation or fight goes on offscreen, with various bodily gestures one might imagine, yet at the same time they are suspended in the void, or immaterialised in a blank mirror. It is the subtle exchange between the actual and the virtual dimensions of time that casts an air of unreality over these and other similar scenes. The empty space functions as a kind of virtual mirror that deactualises the present moment while it is still going on. We are plunged into a sense of déjà-vu, of things already becoming memory at the same time as they happen. In other words, we are brought face to face with the duration of time as pure memory.

In this regard, it is worth taking a close look at the lyrical kernel of the film - the scene in which the young members of the performance troupe run after a freight train passing by the desolate mountain area where the troupe is stranded. The scene's symbolic meaning is obvious: it is a visual embodiment of the experience of waiting, as expressed in the song "Platform", which accompanies a major portion of the scene. The association between the train and the sense of longing is rather conventional. What is extraordinary here is how the scene transforms the commonplace symbol of the train into a veritable experience of waiting. The most crucial contributing element to this is the camera's long, static fixation on the empty mountain landscape preceding the train's arrival. As we wait through the shot, it feels as if we are waiting in the past, into which the present is already passing. We hear the distant shouts of people, the whistle of the train, and the vibration of the railway, all of which indicate motions of the ongoing present. Yet these motions seem to only add more to the stillness of the mountain landscape, with the agitation falling into the void as soon as it rises. When this ordinary, worn-out freight train finally arrives on the scene, our agitation rises to the highest point. Yet so does the sense that our anticipation has long since become stale, that the train has long since gone into the past. The poetic quality of the scene derives ultimately from the tension between the empty landscape and the ongoing present, which gives us an intensified experience of time as pure memory.

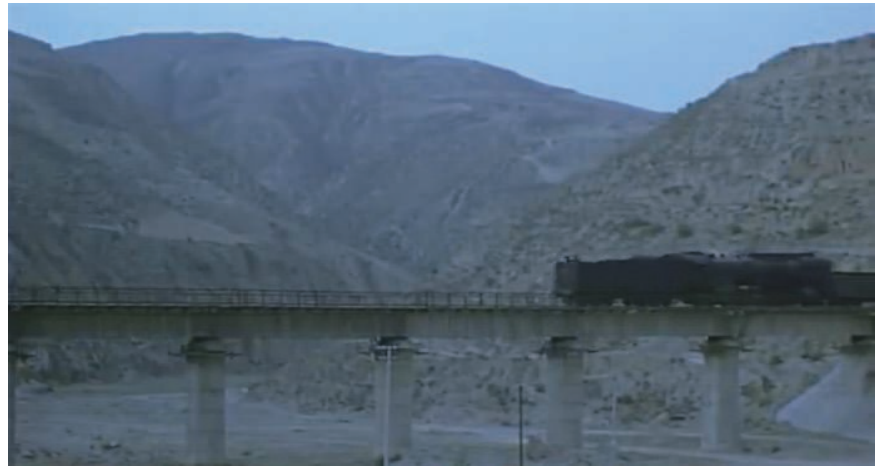

Figure 2. The passing of the train in Platform. Credit: Screenshot by the author.

The presence of the empty space is a major feature Deleuze (1989: 1-8) identifies in the film worlds of Michelangelo Antonioni and Yasujirō Ozu. According to Deleuze, empty space - together with disconnected space - is associated with the invention of the time-image. Unlike the space of realist films, which provides a setting for actions, it offers a direct experience of time. The production of a new type of space, as part of the general shift of the cinematic world, is a direct response to the crisis of meaning in modern societies. In particular, Deleuze connects Ozu's approach with the unique understanding of emptiness in Chinese and Japanese thought, contrasting it with the transcendental horizon of the European tradition. Deleuze's insightful observations seem highly relevant to our understanding of the prominent role empty space assumes in Jia's films. Needless to say, the social-historical world he portrays is the post-socialist era of China, when the entire country turned into a kind of vast demolition and construction site. Meanwhile, although he is bound to an intellectual and aesthetic tradition that values the notion of emptiness, his approach is quite different from Ozu, not least due to the differences between Chinese and Japanese traditions. For our purposes, however, it suffices to acknowledge the general link between his presentation of empty space and the distinct vision of time he wrested from the socio-historical reality of contemporary China.

Besides empty space, another major cinematic device that contributes to capturing the virtual dimension of time is the dissonance between sound and image. A signature feature of Jia's films, as many critics have noted, is his unique use of local dialects and ambient sound (Liu 2006; Berry 2009). One gets a rather raw feeling in hearing the characters speaking their local dialects instead of standard Mandarin, and in hearing the constant flow of traffic, background voices, street broadcasts, radio, soundtracks of TV shows and pop music, etc. Like his use of the long take, the use of local dialects and ambient noises in jia's films has often been understood in terms of a certain faithfulness to reality, in the sense that local dialects are what people actually speak in real life and that the ambient noises truly exist in reality. Yet again, instead of assuming the passive copying of any already existing reality, we must focus on the effect produced at the level of aesthetic construction. The most crucial aesthetic effect of the use of sound in Platform lies in the disjunction between the audio and the visual. In general, the audio is not

7. Besides cases like these, we can also note a similar type in which the camera lingers on for a few seconds after the activity is over, sometimes moving slightly away from the direction in which the characters exit the frame. 
integrated with the visual images in an organic manner, but appears to be somewhat incongruous with the scene in which it occurs. As the audio and the visual are no longer tied together by a narrative cohesion, and each are driven to a point of disconnection, we sense the fissure embedded in the present, or the virtuality of time.

Rather than a transparent tool of communication, local dialects in the film draw attention to themselves for their peculiar intonation and inarticulate quality. The corporeal presence taken up by the local dialects exerts a deterritorialising ${ }^{8}$ effect on the dialogue. While the content of the dialogue is still intelligible to the non-dialect speaker, it is no longer the gravitational centre of a soundtrack subordinated to the visual as part of the narrative whole. Instead, the dialogue has become destabilised from within and has assumed an autonomous status in its disequilibrium. Besides what is said, we are sensitised to the act of speaking that the characters' bodies enact against the silent power of the material environment. What is at stake is not some so-called authenticity; after all, only one out of the four protagonists speaks the Fenyang dialect. Nor is it merely about the stylistic affinity between the roughness of the local dialects and the dilapidated state of the surroundings. Rather, it is the tension between the audio and the visual that matters. In its strangeness, the sound of the speech tears away from the enormous stillness of the world like a muffled cry, or a thwarted protest. Beyond the intelligible content and the stylistic traits of the speech that elucidate the visual, we are presented with the pure enactment of speech as the counterforce of the image. We are brought to see what we do not hear, and to hear what we do not see.

As for the ambient sound, its dissonance with the visual is even more apparent. Take again the memorable city wall scene. Juxtaposed with the poetically rendered visual presentation of the conversation, we hear a steady stream of broadcast advertisements, pop music and news, the sounds of traffic, the loud bangs of construction sites, the muffled voices of people talking, and other barely recognisable background noises. While these background sounds may add a certain documentary quality to the scene, what truly matters is the distance between the image and the sound. In terms of content, what we hear is irrelevant to what we see. Although occupying the same physical space and time, the two elements do not belong to the same psychological and aesthetic register. Rather than functioning as the surrounding milieu that encompasses and permeates the images, the background noises constitute a counterpoint to the visual content and mark out its outer border. Just as the dialogue demarcates the limiting point of the visual world in its enactment of the speech-act, the background noises unsettle the natural extension of the screen-space and expose instead the void that lies at its edge.

The disjunction between the audio and the visual in jia's films accords well with Deleuze's (1989: 241-61) observation regarding the prominent role this feature has assumed in the cinema of the time-image: sound acquires an autonomous status vis-à-vis the visual image in modern cinema. Rather than directing us to see what is in the visual image, as in classical cinema, it becomes a founding act that reveals the deserted layers of time that are buried in the visible world. A similar observation can also be made regarding the effect produced in Jia's use of dissonant sound. The disjunction between the audio and the visual creates the same dynamic we have seen regarding empty space, namely, the exchange between the actual and the virtual. If empty space plays the role of a virtual mirror within the realm of the visual, then dissonant sound might be said to serve as a virtual sounding board from outside the images. As the sound in its dissonance creates a void around the images, we are thrown into a forever recurring struggle between the present moment and its passing. Something is happening, as captured in the sound that has torn itself away from the stillness of the world, yet the event is at the same time muffled and buried before our eyes. The two lovers talk about their love, their voices rising against the silence that surrounds them; the noises flow on in the air, indifferent to the things and people they encircle and invade. By virtue of its strangeness, the sound asserts itself like a pure act of utterance that transforms the space. Yet instead of traversing a continuous time-space created out of the coordination of sound and image, the event fractures and dissolves in the lacunae and fissures of a time-space that constantly moves toward its own limit. In the disjunction between sound and image, we witness the rising of an event that is also falling, or rather, the resistance of the present to the weight of its virtual double.

\section{Weariness, the tired body and the critique of everyday life}

Weariness is an important emotional tone that defines the experience of waiting as depicted in the film, reflecting the existential orientation ${ }^{9}$ that frames the characters' general attitudes towards the world. The scenes may be happy or sad, spirited or dreary, yet these various emotions are all filtered through the tone of weariness. Beneath the protagonists' conscious activities and their accompanying emotional states, we can discern a way of being that prefigures what they do and feel. What they are doing, simply, is waiting in weariness.

Weariness is the affective state of waiting, precisely because waiting discloses to us the virtuality of time. One feels weary whenever what is to happen will not lead to any change, but rather seems to have already become part of the determined past. It is not an excessive amount of activity that makes one weary, but the sense that nothing one does or can do would make any difference. An action demands engagement; the more difficult and demanding an action is, the more engaged one has to be. In waiting, because we are disengaged from action and are confronted instead with the pressure of time, weariness weighs upon us with the painful realisation of the futility of action. Weariness is not the result of action, but is rooted in the impossibility to act. Ultimately, it is time that wears us down - the time that is devoid of action, that carries the abyss of the past within the present at the same time as it presses into the future.

The tired bodies that inhabit the film are the direct embodiment of weariness. Rather than centres of action that transform the world they traverse, the characters move about the space with a marked passivity. Tremendous historical changes are happening to the small city they live in, yet while they are not insensitive to the new trends of life, they do not ride the tides, but are merely carried along and even pushed aside. In this regard, it is particularly important to note the road trip that structures the second half of the film. Shortly before the midpoint of the film, the privatised performance troupe leaves the city on a tour. Until the protagonists' final return at the end, the troupe moves from place to place, to locations that become increasingly remote and hostile, with their one visit back home marked by an equally desolate and alienating feeling. The characters gradually lose meaningful interactions with the environment in which they dwell and are reduced to a state of powerlessness. Towards the end, the

8. My discussion refers to Deleuze's (1986) seminal interpretation of Kafka as a case of "minor literature."

9. It is close to what Heidegger (2010) calls the "attunement" of being-in-the-world, which denotes the general affective condition that structures our ways of relating to the world. 
narrative gets increasingly loose, and all that remains are fragmented scenes from an apparently disintegrating journey. In one of these fragments, a long take of more than a minute, we are presented with a still shot of a barren, empty landscape, with a truck appearing far away on the horizon, driving slowly towards the camera and then driving back to where it came from. As the truck passes us again on its way back, the cover on its bed is thrown open and we see its passengers - presumably the troupe members - popping into view. They appear dishevelled and perplexed as they are carried away from us on the vehicle. The fragility of the human figures captured against the backdrop of the barren, empty landscape and the seemingly senseless movement of the truck is one of the film's most expressive images of the immense weariness that afflicts their state of being. Embedded in their tired bodies, one might say, is the abyss of time itself.

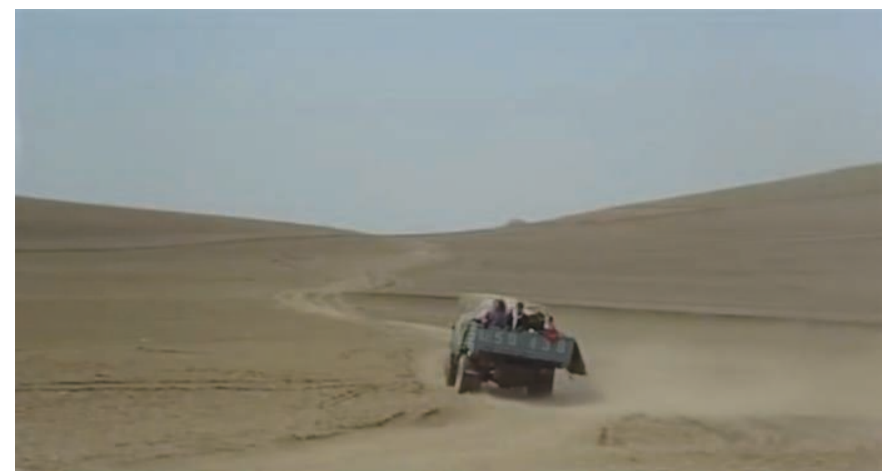

Figure 3. Long take and weariness in Platform. Credit: Screenshot by the author.

If the form of the road trip facilitates the portrayal of the diminishing power of the human subject in relation to the environment, it is in everyday life itself that the film finds the breeding ground for such an affliction. We have shown how the use of empty space and dissonant sound disrupts the conventional perception of the temporal-spatial continuum of the world and exposes the lacunas and fissures embedded in our everyday existence. This disruption also occurs in the everyday attitude of the body. Specifically, the tired body's fight against the virtual abyss of time is made particularly visible through the impassive and prosaic manner that marks the body's movement.

The acting style in Platform, as in almost all of Jia's other films, is often characterised as understated. The characters appear to act in a rather impassive, prosaic fashion. While it might again be tempting to interpret such an acting style as aiming for a faithful copy of reality, since we are indeed less prone to dramatic movements in our everyday life, the true aesthetic function of this style of acting is to capture the gaps and lacunae that inhabit the everyday attitude of the body. To be sure, the characters' movements do generally conform to the conventional logic of spatialpsychological continuity. However, by virtue of the attenuation of meaning in these movements, they are not fused together in a tight-knit fashion, but tend towards fragmentation and dispersion. A motion that does not lead anywhere, a gaze scattered in the void, a gesture that seems to be automatic and devoid of meaning - these kinds of bodily movements populate the film and function like open apertures that rarefy the pulsing threads of the everyday world. If the impassive, prosaic movements of the body are subjected to the integrating power of the spatial-psychological continuum of the ordinary, they also carry a centrifugal force that unearths the little holes and gaps that lie beneath the matter-of-fact conventionality of our everyday life.
Everyday life has emerged as a central area of research in the field of China studies in recent years. Drawing upon contemporary theories of everyday life, especially as developed by Henri Lefebvre and Michel de Certeau, current scholarship generally sees everyday life as a privileged site from which to explore the internal contradictions and unfulfilled promises of modernity (Lu 1999; Dong and Goldstein 2006; Wang 2012). There are two major merits to these studies. First, they shed light on the crucial link between contemporary re-evaluations of everyday life and the experience of modernity. While everyday life has always been part of human culture, it is only in recent times, when it is increasingly integrated into the rationalisation process of modernity, that it comes to be valued as the concrete embodiment of lived experience. Second, by attending to the insignificant details of quotidian life, they bring into view a realm of cultural practices that cannot be assimilated by modernity's claim to progress and that harbours the possibility of new forms of perceiving and feeling.

While I share the basic premises of the existing scholarship, my own focus in this article is on the existential dimension of the banality of everyday experience, a dimension that is central to theories of everyday life, yet which is somewhat neglected in the field of China studies. Beyond the specific socio-historical content of the realm of everyday life in contemporary China, it is also important to acknowledge the experience of banality that constitutes the existential core of modern quotidian living. In the following pages, I will attempt to further elucidate the meaning this dimension acquires in Jia's films in light of the insightful observations Deleuze (1989: 3) has made on the crucial role played by the depiction of "everyday banality" in post-war cinema:

(...) if everyday banality is so important, it is because, being subject to sensory-motor schemata which are automatic and pre-established, it is all the more liable, on the least disturbance of equilibrium between stimulus and response (...), suddenly to free itself from the laws of this schema and reveal itself in a visual and sound nakedness, crudeness and brutality which make it unbearable, giving it the pace of a dream or a nightmare.

The "sensory-motor schemata" Deleuze refers to in this passage corresponds to the conventional understanding of time - as a linear succession of discrete moments - that has been the basic point of contrast in our foregoing discussion of the film's presentation of the duration of time. For Deleuze, the sensory-motor schemata is the organising principle of the world based on the linear, causal mode of temporality. According to this principle, the world is structured by the practical application of perceptions and actions (sensory and motor faculties) to fulfil human needs, desires, purposes, etc. To translate Deleuze's comment into the terms of our discussion, what he says is essentially that, because we are not actively engaged in purposeful actions but are passively subjected to the rule of habits and customs in our everyday life, it is in this realm that the linear, causal link we normally assume among things is prone to be broken down. In the automatization of our daily activity, as purpose and meaning are reduced to the force of habit, we are brought to the edge beyond which reigns the abyss of time.

The impassive, prosaic movements of the body that we find in Platform, especially those that border on the automatic and the purposeless, enable us to sense precisely the kind of potential breakdown that Deleuze locates at the heart of the everyday world. A major accomplishment of the film lies in its ability to capture the gaps and lacunae that inhabit the everyday 
attitude of the body and, in this sense, the duration of time that is concealed beneath the mundane happenings of everyday life. This particular approach to everyday life is rather notable in the context of contemporary Chinese literature and film, where the representation of everyday life has emerged as an important locus of creative efforts in recent decades. The terrain is vast to traverse, but it seems possible to identify two major tendencies. One is to take everyday life as a realm of innocence and simplicity that is constantly threatened by the intrusion of politics and history (for instance in Yu Hua's 余華 novel To Live and its filmic adaptation by Zhang Yimou 張藝謀). The other is to embrace the mundane materiality of everyday life, refusing to subject it to the critique of any kind of spiritual idealism, for instance in the so-called "new realism" (Xin xieshi zhuyi 新寫實主義) literary school (Liu Zhenyun 劉震雲 and Chi Li 池莉). In different ways, both trends take issue with the traditional view of culture that relegates everyday life to the lowest stratum of human culture and instead asserts the irreducible value of everyday life as a fundamental aspect of human existence. On this basic point, Jia's film clearly belongs to this new direction of thinking. Compared to the two other tendencies, however, Jia's approach seems to carry higher critical value. Rather than reducing everyday life to an empty emblem, the sole function of which is to signify the other side of politics and history, or admitting only the mundane materiality of everyday life to the exclusion of higher spiritual values of culture, Jia's film presents a phenomenological critique of everyday life as the sedimentation and automatization of cultural norms. While the dominant trends attempt to cut off the tie between everyday life and other realms of culture, Jia takes everyday life as a privileged ground to expose the ingrained conventionality of cultural values and thereby also the potential locus of radical cultural change.

Everyday life is unbearable, as it is presented in Platform, in the sense that our commonly accepted cultural norms fall to the status of mere convention and can no longer supply meaning to our life. In terms of our experience of time, everyday life is unbearable because it is filled with the intervals of waiting, which means that, in place of a temporal continuum on the basis of which we might structure our existence, it reveals the little holes and gaps of time that make us weary of any possible action. This is the most valuable point that we can draw from the film. The critique of everyday life we find in the film is no longer premised on the superiority of higher realms of culture, as is the case with the traditional critique. Nor does the film, on the other hand, denounce all quests of the spiritual kind in favour of the sheer materiality of everyday existence. Rather, it presents us with a critique from within the realm of everyday life - not as the antithesis of spiritual values of a higher order, but as the very site where the platitude of existing norms of culture is laid bare and where the unbearable pressure of time forces us to question the value of all existing possibilities.

\section{Conclusion}

Where we find the unbearable, we may also find something new being created. Bergson takes the duration of time as the source of all unforeseeable creations. In the same sense, Deleuze (1989: 19) emphasises the "inexhaustible possibility that constitutes the unbearable." In one of the scenes we mentioned earlier, the one in which the female protagonist dances to the radio in her office, we witness how the body, while languidly executing daily routines of office work, suddenly bursts into dance. The sudden transformation of the everyday movements of the body into the creative act of dancing, as presented in this scene, might be said to be fully indicative of the creative potential harboured in the unbearable banality of everyday life. While such moments of eruption are rare in most of Jia's films, including Platform, we still sense that a certain eruptive force is fermenting in the silent despair that permeates the everyday space they depict. In this regard, $A$ Touch of Sin, although marked by an ostensible shift of style, can be seen as bearing a deep connection with his earlier films. All four episodes that comprise the film, irrespective of their specific differences, might be characterised as silent despair leading to sudden eruption. Although the violent eruptions of some of its protagonists - as in the case of Dahai and Xiaoyu - are directly triggered by violence inflicted upon them, these moments of eruption should not be understood in the conventional sense of dramatic action. Rather, they truly disclose how the silent despair of everyday existence can give rise to unforeseeable eruptions, in a similar way to what we find in the ending of Chantal Akerman's Jeanne Dielman, 23, Quai du Commerce, 1080 Bruxelles. It is rather extraordinary that jia would find inspiration in traditional Chinese novels and drama as well as in the wuxia 武俠 (martial arts) genre of film, both in the theme and structure of the narrative, and in the highly stylised presentation of acts of revenge. As is shown particularly clearly in the episodes of Dahai and of Xiaoyu, he finds a deep affinity between these acts of violence and the theme of revenge in the folk tradition. Beyond the easily identified specific intertextual references, it is crucial to note the intentionally surreal manner in which the moments of revenge are presented. In transposing these scenes of violence into another level of reality, one that taps into the imaginary world of revenge that has been built up in the folk tradition for thousands of years, $A$ Touch of $\operatorname{Sin}$ brings to the surface the creative force fermenting beneath the unbearable banality of everyday life. Looking back from the vantage point of this later film, we can also re-affirm the power of resistance that is embedded in jia Zhangke's early works. As the most concentrated expression of the unbearable banality of everyday life, Platform offers an extraordinary act of resistance from the heart of the experience of time.

\section{Acknowledgements}

I am grateful to Todd Foley for proofreading and commenting on this article. I would also like to thank the two anonymous reviewers for their critique and suggestions.

I Wenjin Cui is Assistant Professor of Chinese at the University of New Hampshire. Murkland Hall G10E, UNH, Durham, NH03824, United States (wenjin.cui@unh.edu).

Manuscript received on 31 January 2019. Accepted on 8 August 2019.

\section{Films cited:}

AKERMAN, Chantal. 1975. Jeanne Dielman, 23, Quai du Commerce, 1080 Bruxelles, $201 \mathrm{~min}$.

JIA, Zhangke 賈樟柯. 1997.Xiao Wu 小武 (Xiaowu), 108 min. JIA, Zhangke 賈樟柯. 2000. Platform 站台 (Zhantai), 154 min. JIA, Zhangke 賈樟柯. 2004. The World 世界 (Shijie), 143 min. JIA, Zhangke 賈樟柯. 2013. A Touch of Sin 天注定 (Tianzhuding), 133 $\min$.

ZHANG, Yimou 張㙯謀. 1994. To Live 活著 (Huozhe), $132 \mathrm{~min}$. 


\section{References}

BERGSON, Henri. 1998. Creative Evolution. Translated by Arthur Mitchell. Mineola, NH: Dover Publications.

BERGSON, Henri. 2007. The Creative Mind. Translated by Mabelle L. Andison. Mineola, $\mathrm{NH}$ : Dover Publications.

BERRY, Michael. 2009. Xiao Wu, Platform, Unknown Pleasures: Jia Zhangke's 'Hometown Trilogy'. London: Palgrave Macmillan.

BURCH, Noël. 1979. To the Distant Observer: Form and Meaning in the Japanese Cinema. Revised and edited by Annette Michelson. Berkeley: University of California Press.

BYRNES, Corey. 2012. "Specters of Realism and the Painter's Gaze in Jia Zhangke's 'Still Life'." Modern Chinese Literature and Culture 24(2): $52-$ 93.

CHEUNG, Esther M.K. 2010. "Realisms within Conundrum: The Personal and Authentic Appeal in Jia Zhangke's Accented Films." China Perspectives 1(81): 11-20.

CUI, Shuqing. 2006. "Negotiating In-Between: On New-generation Filmmaking and jia Zhangke's Films." Modern Chinese Literature and Culture 18(2): 98-130.

DELEUZE, Gilles. 1986. Kafka: Toward a Minor Literature. Translated by Dana Polan. Minneapolis: University of Minnesota Press.

DELEUZE, Gilles. 1988. Bergsonism. Translated by Hugh Tomlinson and Barbara Habberjam. New York: Zone Books.

DELEUZE, Gilles. 1989. Cinema 2: The Time-Image. Translated by Hugh Tomlinson and Robert Galeta. Minneapolis: University of Minnesota Press.

DE LUCA, Tiago. 2013. Realism of the Senses in World Cinema: The Experience of Physical Reality. London: I.B. Tauris.

DONG, Madeleine Yue, and Joshua L. GOLDSTEIN. 2006. Everyday Modernity in China. Seattle: University of Washington Press.

HEIDEGGER, Martin. 2010. Being and Time. Translated by Joan Stambaugh. Albany: State University of New York Press.
IIA, Zhangke. 2001. Interview with Stephen Teo. "Cinema with an Accent - Interview with jia Zhangke, Director of Platform." Senses of Cinema (July). http://sensesofcinema.com/2001/feature-articles/zhangke_ interview/ (accessed on 7 December 2018).

JIA, Zhangke. 2003. Interview with Shelly Kraicer. "An Interview with Jia Zhangke." Cineast (Winter): 30-3.

JIA, Zhangke. 2009. 賈想1996-2008: 賈樟柯電影手記 (Jia xiang 19962008: Jia Zhangke dianying shouji, Jia thinks 1996-2008: Jia Zhangke's Cinema Handbook). Beijing: Peking University Press.

LI, Jie. 2009. "Home and Nation Amid the Rubble: Fei Mu's Spring in a Small Town and jia Zhangke's Still Life." Modern Chinese Literature and Culture 21(2): 86-125.

LIU, Jin. 2006. "The Rhetoric of Local Languages as the Marginal: Chinese Underground and Independent Films by Jia Zhangke and Others." Modern Chinese Literature and Culture 18(2): 163-205.

LU, Hanchao. 1999. Beyond the Neon Lights: Everyday Shanghai in the Early Twentieth Century. Berkeley: University of California Press.

MCGRATH, Jason. 2007. "The Independent Cinema of Jia Zhangke: From Postsocialist Realism to a Transnational Aesthetic." In Zhang Zhen (ed.), The Urban Generation: Chinese Cinema and Society at the Turn of the Twenty-first Century. Durham, NC: Duke University Press. 81-114.

NAGIB, Lúcia. 2011. World Cinema and the Ethics of Realism. New York: Continuum.

VEG, Sebastian. 2007. "From Documentary to Fiction and Back: Reality and Contingency in Wang Bing's and Jia Zhangke's films." China Perspectives 3(71): 130-7.

WANG, Ban. 2012. "Photographical History, Everyday Life, and Memory: Wang Anyi as a Storyteller." Journal of Historical Sociology 25(2): 18398.

ZHANG, Xudong. 2010. "Poetics of Vanishing: The Films of Jia Zhangke." New Left Review 63 (May-June): 71-88.

ZHENG, Aili. 2013. "The Realism of Compositional Documentary: Jia Zhangke's I Wish I Knew." Pacific Coast Philology 48(1): 88-108. 